\title{
Mucocutaneous disorders in HIV/AIDS at a tertiary care hospital in Nepal: An observational study
}

\section{Prabhat Singh Rajput, Anil Kumar Das, Upama Paudel, Sudip Parajuli}

\author{
Maharajgunj Medical Campus, Institute of Medicine, Maharajgunj, Kathmandu, Nepal
}

Corresponding author: Dr. Sudip Parajuli, E-mail: sudipparajuli@gmail.com

\begin{abstract}
Background: Mucocutaneous manifestations in HIV infections are common. However, they have not, so far, been studied in Nepal. The aim of this study was, therefore, to describe mucocutaneous manifestations in Nepalese HIV patients. Materials and Methods: The following is a hospital-based, descriptive, cross-sectional study conducted in the Department of Dermatology and Venereology and Antiretroviral Treatment (ART) Center of Tribhuvan University Teaching Hospital (TUTH) from May 2017, through October 2018. Patients aged 16 years and above diagnosed with HIV were included in the study, for whom history and clinical examinations were performed. The study variables were age, sex, a clinical diagnosis of dermatological problems, clinical stages of HIV/AIDS, as per the World Health Organization (WHO) classification criteria, and the CD4 count. Results: A total of 52 patients were included in the study. The mean age upon presentation was 38.77 \pm 10.9 years. The mean CD4 count was $464.27 \pm 255.13$. Females were more affected than males (female:male $=1.4: 1)$. Mucocutaneous manifestations were the following: fungal infections $(10 ; 19.3 \%)$, viral infections $(6 ; 11.6 \%)$, parasitic infestations (3; 5.8\%), bacterial infections $(4 ; 7.7 \%)$, sexually transmitted infections $(2 ; 3.8 \%)$, seborrheic dermatitis $(3 ; 5.8 \%)$, idiopathic pruritus $(3 ; 5.8 \%)$, recurrent oral ulcers $(3 ; 5.8 \%)$, urticaria $(3 ; 5.8 \%)$, pruritic papular eruptions $(2 ; 3.8 \%)$, eczemas $(2 ; 3.8 \%)$, acne $(2 ; 3.8 \%)$, angular cheilitis $(2 ; 3.8 \%)$, xerosis cutis $(2 ; 3.8 \%)$, and others $(5 ; 9.6 \%)$. Conclusions: The study showed that fungal infections are common in HIV patients, followed by viral infections and parasitic infestations. Seborrheic dermatitis, idiopathic pruritus, recurrent oral ulcers, and urticaria were found to be common inflammatory skin diseases in HIV.
\end{abstract}

Key words: Antiretroviral agents; CD4+T lymphocytes; HIV; Skin diseases; World Health Organization

\section{INTRODUCTION}

Mucocutaneous manifestations are common in HIV infections and may sometimes be their earliest manifestations. A variety of skin disorders occur during the course of HIV, such as infectious skin diseases, noninfectious skin diseases, and malignant skin conditions [1]. It is reported that almost $90 \%$ of people living with HIV (abbreviated to PLHIV) will develop skin symptoms during the course of the disease [2]. These manifestations not only act as markers but also reflect the underlying immune status and help to determine the stage of the disease. Treatment of HIV used to be based on clinical HIV staging and the CD4 count, the former applied to the majority of mucocutaneous manifestations. At present, the World Health Organization (WHO) recommends treating all HIV patients with antiretroviral therapy (ART), regardless of staging and the CD4 count [3]. Because of the "test and treat" policy, authors have seen the changing nature of mucocutaneous manifestations in HIV, probably because of early diagnosis and treatment, and this has not yet been documented. To the best of our knowledge, no studies on mucocutaneous manifestations in HIV infection have been conducted in Nepal. The following study was, therefore, undertaken to determine the pattern of various mucocutaneous manifestations in Nepalese patients with HIV/AIDS.

\section{MATERIALS AND METHODS}

The following is a hospital-based, descriptive, crosssectional study conducted in the Department of

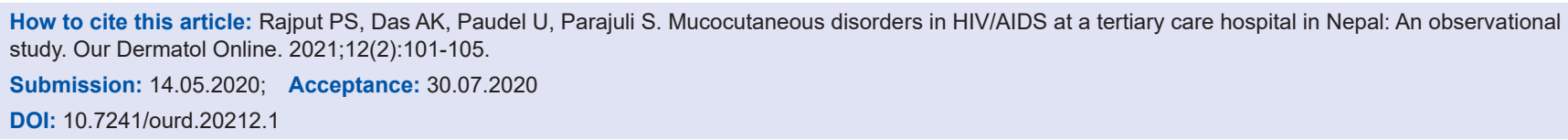


Dermatology and Venereology and Antiretroviral Treatment (ART) Center of Tribhuvan University Teaching Hospital (TUTH) from May 2017, through October 2018. This center is one of the tertiary care centers for treatment of people living with HIV (PLHIV) located in Nepal. Patients aged 16 and above, diagnosed with HIV-irrespective of their ART status-and complaining of skin and venereal problems were included in the study. These patients were diagnosed based on the Nepal national algorithm for the diagnosis of HIV. In Nepal, three rapid test kits are used for the diagnosis of HIV: Determine HIV-1/2 (Assay 1), Uni-Gold HIV-1/2 (Assay 2), and Stat-Pak HIV-1/2 (Assay 3) [3]. The diagnosis of HIV is given only when these three assays are positive in serial testing. History and clinical examinations were performed on these patients, and the following variables were studied: age, sex, a clinical diagnosis of dermatological problems, clinical stages of HIV/ AIDS, as per the WHO classification criteria, and the CD4 count. Any active lesion or scarring of the skin and mucosa observed in HIV-positive patients were labeled as mucocutaneous manifestations of HIV. Dermatological diagnoses were confirmed by two consultant dermatologists after performing examinations of all patients in daylight. In the case of more than one diagnosis, each manifestation was counted separately. Skin problems before the diagnosis of HIV and patients with systemic diseases were excluded from the study. All these findings were documented in a pro forma. Investigations were pursued only in cases deemed relevant and necessary for diagnosis. All the data was processed by the software SPSS Statistics, version 20.0. Descriptive analysis of the data was performed. Ethical approval was taken from the Institutional Review Committee of the Institute of Medicine before the study.

\section{RESULTS}

Out of the 52 patients who participated in the study, $31(59.6 \%)$ were females and $21(40.4 \%)$ were males (female:male $=1.4: 1)$. The mean age upon presentation was $38.77 \pm 10.9$ years. Overall, infectious skin diseases $(\mathrm{n}=27)$ were almost as common as noninfectious skin diseases $(\mathrm{n}=25)$ (Table 1$)$. Fungal infections (19.3\%) were the predominant manifestations among infections, whereas seborrheic dermatitis, idiopathic pruritus, recurrent oral ulcers, and urticaria were the predominant manifestations among noninfectious skin disorders, each accounting for $5.8 \%$ of all manifestations
Table 1: Patterns of mucocutaneous disorders in HIV

\begin{tabular}{|c|c|c|c|c|c|}
\hline $\begin{array}{l}\text { Infectious skin } \\
\text { diseases }\end{array}$ & $\begin{array}{c}\text { Stage } \\
1(n)\end{array}$ & $\begin{array}{l}\text { Stage } \\
2(n)\end{array}$ & $\begin{array}{c}\text { Stage } \\
3(n)\end{array}$ & $\begin{array}{c}\text { Stage } \\
4(n)\end{array}$ & $\begin{array}{c}\text { Frequency } \\
\text { n (\%) }\end{array}$ \\
\hline Fungal & 1 & 4 & 1 & 4 & $10(19.3)$ \\
\hline Viral & 0 & 1 & 1 & 4 & $6(11.6)$ \\
\hline Parasitic & 0 & 2 & 1 & 0 & $3(5.8)$ \\
\hline Bacterial & 0 & 0 & 3 & 1 & $4(7.7)$ \\
\hline $\begin{array}{l}\text { Sexually Transmitted } \\
\text { Infections }\end{array}$ & 0 & 0 & 0 & 2 & $2(3.8)$ \\
\hline \multicolumn{6}{|c|}{ Non-infectious skin diseases } \\
\hline Seborrheic dermatitis & 0 & 1 & 0 & 2 & $3(5.8)$ \\
\hline Idiopathic Pruritus & 0 & 1 & 2 & 0 & $3(5.8)$ \\
\hline Recurrent oral ulcers & 0 & 2 & 0 & 1 & $3(5.8)$ \\
\hline Urticaria & 1 & 0 & 1 & 1 & $3(5.8)$ \\
\hline $\begin{array}{l}\text { Pruritic papular } \\
\text { eruptions }\end{array}$ & 0 & 1 & 0 & 1 & $2(3.8)$ \\
\hline Eczemas & 1 & 1 & 0 & 0 & $2(3.8)$ \\
\hline Acne & 1 & 1 & 0 & 0 & $2(3.8)$ \\
\hline Angular cheilitis & 0 & 1 & 1 & 0 & $2(3.8)$ \\
\hline Xerosis cutis & 0 & 0 & 0 & 2 & $2(3.8)$ \\
\hline Others & 3 & 1 & 0 & 1 & $5(9.6)$ \\
\hline Total & 7 & 16 & 10 & 19 & $52(100)$ \\
\hline
\end{tabular}

(Table 1). Clinical staging (as per the WHO) of these patients was done, showing that $7(13.5 \%)$ patients were in stage $1,16(30.8 \%)$ in stage $2,10(19.2 \%)$ in stage 3 , and $19(36.5 \%)$ in stage 4 . One patient with each of the following diseases was in stage 1: pityriasis versicolor, miliaria rubra, chronic spontaneous urticaria, dyshidrotic eczema, lipodystrophy, rosacea, and acne. Onychomycosis $(n=1)$, idiopathic pruritus $(n=1)$, oral or vaginal candidiasis $(\mathrm{n}=1)$, tinea corporis/ cruris $(n=1)$, recurrent oral ulcers $(n=2)$, scabies $(\mathrm{n}=2)$, allergic contact dermatitis $(\mathrm{n}=1)$, pruritic papular eruptions $(n=1)$, angular cheilitis $(n=1)$, herpes simplex $(\mathrm{n}=1)$, acne $(\mathrm{n}=1)$, and melasma $(\mathrm{n}=1)$ were seen in stage 2 . Idiopathic pruritus $(\mathrm{n}=2)$ and folliculitis $(\mathrm{n}=2)$ were more common in stage 3 , followed by one per case of tinea, bacillary angiomatoses, chronic spontaneous urticaria, angular cheilitis, pediculosis, and herpes zoster. Seborrheic dermatitis $(n=2)$, herpes labialis $(n=2)$, pityriasis versicolor $(n=2)$, verruca vulgaris $(n=2)$, and xerosis cutis $(n=2)$ were commonly seen in stage 4 (advanced HIV), followed by one per case of oral or vaginal candidiasis, tinea, condyloma acuminata, recurrent oral ulcers, molluscum contagiosum, chronic spontaneous urticaria, pruritic papular eruptions, polymorphic light eruptions, and acute paronychia. These cutaneous findings are shown in Table 1.

The mean CD4 count in our study was $464.27 \pm 255.13$, ranging between 10 and 964.10 patients $(19.2 \%)$ had a CD4 count of less than 200, and 42 patients (80.8\%) had a CD4 count of more than 200 (Table 2). 
Table 2: Mucocutaneous manifestations in relation to the CD4 count

\begin{tabular}{lcc}
$\begin{array}{l}\text { Mucocutaneous } \\
\text { manifestations }\end{array}$ & $\begin{array}{c}\text { CD4 less than } \\
\mathbf{2 0 0}(\mathbf{n})\end{array}$ & $\begin{array}{c}\text { CD4 more than } \\
\mathbf{2 0 0}(\mathbf{n})\end{array}$ \\
\hline Fungal & 1 & 9 \\
Viral & 2 & 4 \\
Parasitic & 0 & 3 \\
Bacterial & 2 & 2 \\
STIs & 0 & 2 \\
Noninfectious skin diseases & 5 & 22 \\
Total & 10 & 42 \\
\hline
\end{tabular}

\section{DISCUSSION}

In our study, overall infectious skin diseases in HIV patients $(\mathrm{n}=27)$ were almost as common as inflammatory skin diseases $(\mathrm{n}=25)$. Fungal diseases $(\mathrm{n}=10)$ were common skin infections, followed by viral $(n=6)$ and bacterial $(n=6)$ infections. Different types of inflammatory skin diseases were seen, among which seborrheic dermatitis, idiopathic pruritus, recurrent oral ulcers, and urticaria were the predominant cutaneous presentations. We feel that, because of the early introduction of antiretroviral therapy (ART) in all the patients, general dermatoses unrelated to HIV were as common as those related to HIV.

Seborrheic dermatitis is a manifestation of stage 2 HIV and accounts for a $1-10 \%$ prevalence in the general adult population [4]. Seborrheic dermatitis was present in $5.8 \%$ of our cases, which is a smaller percentage than that reached by other studies (up to $11.9 \%$ ) [5]. Similarly, onychomycosis was present in $3.8 \%$ of our cases, again, less frequently than in other studies $(2-50 \%)$ [6].

Pruritus, which is usually caused by immune dysregulation [7], was seen in 5.8\% of our cases. Even the prevalence of pruritus in our study was lower compared to other studies, which estimate it at approx. $12-45 \%$ [8].

The lower prevalence of the dermatoses observed in our study could be attributed to the early initiation of ART in our patients, but a lower sample size could also be a contributing factor.

In our study, fungal infections were common among the infectious skin diseases. Tinea cruris, tinea corporis, onychomycosis, and pityriasis versicolor together accounted for $15.4 \%$ of the cases. This is similar to a study that estimated it at approx. 16.3\% [2], but, still, higher than other studies [9], possibly because our agricultural society is more exposed to soil, water, and animals, which are common sources of these infections.

Bacillary angiomatosis occurs commonly in HIV patients with severe immune suppression $[10,11]$. It is a rare entity with a prevalence of as low as 1.2 per 1000 HIV cases. We had one such case $(1.9 \%)$ of bacillary angiomatosis in our study. The reason for the higher prevalence of this condition needs further research in the future.

Sexually transmitted infections (STIs) are one of the important manifestations of HIV. The prevalence of condyloma acuminata in HIV ranges from $8.8 \%$ to $53 \%[12,13] .1 .9 \%$ of our cases suffered from condyloma acuminata. The fact that our patients were welleducated on barrier contraceptive measures along with receiving positive prevention at our ART center could have contributed to the lower rates of STI in our study.

$5.8 \%$ of our cases had recurrent oral ulcerations seen in clinical HIV stage 2. 3.8\% had herpes labialis, similar to the report by an Indian study [1]. HIV selectively infects, depletes, and/or dysregulates different human immune systems, particularly mucosal sites, and damages mucosal barriers [14]. Such damage to the mucosal epithelium was perhaps the cause of the recurrent oral ulcerations and herpes labialis seen in our patients.

The frequency of pruritic papular eruptions (PPEs) was $3.8 \%$ in our study. PPEs usually appear as papules and plaques that are usually widespread, skincolored to erythematous, and usually bearing signs of excoriations [15]. Their presence after at least 6 months of ART has been proposed as one of the several markers of treatment failure [15]. The frequency of PPEs has been reported by some studies to be as high as $56 \%$ [16]. The frequency of PPEs appears to be low in our case because all the patients were on ART prior to the inclusion in the study.

Xerosis was seen in $3.8 \%$ of our cases. The prevalence of xerosis in HIV varies from $2.8 \%$ to $73.3 \%$ [2]. It is one of the most common skin manifestations in HIV and is a common cause of pruritus in HIV patients. Impaired water metabolism in the viable epidermis and reduced dermal lipids are responsible for HIVassociated xerosis [17].

Herpes zoster was seen in $1.9 \%$ of our cases. It occurs more frequently in older people and those with cellular 
immunodeficiency [18]. In PLHIV, a prevalence of $8 \%$ has been found [19]. The lower frequency of herpes zoster in our study could again be attributed to early ART in our study population.

Parasitic infestations accounted for $5.8 \%$ of our cases and included scabies and pediculosis. The prevalence of scabies has been reported by other studies to be $0.4-5.1 \%$ [2]. Scabies can be seen in an atypical form as crusted scabies in patients with HIV. Our cases of scabies had a presentation as of immunocompetent patients.

Some of our patients displayed acne and polymorphic light eruptions, which are common in the general Nepalese population, and, according to the authors, might not be significant presentations, or it might be that HIV displays the prevalent dermatoses of the general population.

Our study showed that 10 patients (19.2\%) had a CD4 count of less than 200, and 42 patients (80.8\%) had a CD4 count of more than 200. Surprisingly, all the manifestations (infectious and noninfectious skin diseases) were seen in patients with a higher CD4 count, except for bacterial infections (equal number of infections in the two groups). This is an important finding as it suggests and proves that starting ART in the early stages of HIV prevents mucocutaneous manifestations.

This study shows the pattern of cutaneous manifestations in HIV patients of a Nepalese center and is the first study to have been conducted in Nepal. The lower frequency of mucocutaneous manifestations in our study compared to the known manifestations of HIV can be attributed to a smaller number of HIV cases in our study, which was one of its limitations. Furthermore, because of multiple diagnoses, a statistical correlation between different study variables was not ascertained. Moreover, all the patients were on ART, which could have contributed to immune restoration and, consequently, less frequent manifestations of skin diseases. This points toward the changing mucocutaneous manifestations in HIV in a post "treat all patients" scenario. However, further studies with large numbers of HIV patients and their correlation with staging and the CD4 count will be required in the future to prove these important observations.

\section{CONCLUSION}

Our study showed a variety of mucocutaneous manifestations in different stages of HIV. The pattern of skin diseases seems to be distributed widely, ranging from infectious to inflammatory, with infectious diseases being in our study as common as inflammatory skin diseases. The frequency of all mucocutaneous manifestations appeared to be smaller compared to other studies because of the possible role of the "treat all" policy, proving the observation of the changing nature of skin diseases in HIV patients.

\section{ACKNOWLEDGMENT}

We would like to thank Dr. Amod Poudyal of the Central Department of Public Health of the Institute of Medicine for statistical help.

\section{Statement of Human and Animal Rights}

All the procedures followed were in accordance with the ethical standards of the responsible committee on human experimentation (institutional and national) and with the 2008 revision of the Declaration of Helsinki of 1975.

\section{Statement of Informed Consent}

Informed consent for participation in this study was obtained from all patients.

\section{REFERENCES}

1. Chandrakala C, Parimalam K, Wahab AJ, Anand N. Correlating CD4 count with mucocutaneous manifestations in HIV-positive patients: A prospective study. Indian J Sex Transm Dis AIDS. 2017;38:128-35.

2. Boushab BM, Malick Fall FZ, Ould Cheikh Mohamed Vadel TK, Ould Cheikh Melaïnine ML, Maazouz MV, Savadogo M, et al. Mucocutaneous manifestations in human immunodeficiency virus (HIV)-infected patients in Nouakchott, Mauritania. Int J Dermatol. 2017;56:1421-4.

3. Government of Nepal, Ministry of Health and Population. National Consolidated Guideline for Treating and Preventing HIV in Nepal. Kathmandu, Nepal: National Center for STD and AIDS Control; 2014.

4. Tamer F. Relationship between diet and seborrheic dermatitis. Our Dermatol Online. 2018;9:261-4.

5. Swamiappan M, Chandran V, Ramasamy S, Sridhar V, Thiyagarajan V. Pattern of mucocutaneous manifestations of HIV infected patients: a retrospective study. J Evol Med Dent Sci. 2016;5:4060-63.

6. Kaur T, Puri N. Onychomycosis - A clinical and mycological study of 75 cases. Our Dermatol Online. 2012;3:172-7.

7. Ekpe O, Forae GD, Okwara B, Okwuonu CG, Madubuko RC. Frequency and clinico-topographic distribution patterns of pruritic papular eruption in HIV patients in a Nigerian Tertiary Hospital. Our Dermatol Online. 2019;10:333-7.

8. Xu T, Shetty AK, Badiger S, Chan YH, Yosipovitch G. Prevalence and characteristics of pruritus and association with quality of life in people living with HIV: A cross-sectional study. J Pain Symptom Manage. 2018;55:e4-e7.

9. Guarner J. Human immunodeficiency virus and fungal infections. Semin Diagn Pathol. 2017;34:325-31.

10. Akram SM, Anwar MY, Rawla P. Bacillary Angiomatosis. [Updated 


\section{www.odermatol.com}

2020 Jun 27]. In: StatPearls [Internet]. Treasure Island (FL): StatPearls Publishing; 2020 Jan.

11. Madua MC. Bacillary angiomatosis: A rare finding in the setting of antiretroviral drugs. S Afr Med J. 2015;105:6-7.

12. Kreuter A, Wieland U. Condylomata acuminata of HIV-positive men may harbour focal areas of dysplasia: relevant implications for the management of human papillomavirus-induced disease in high-risk patients. Br J Dermatol. 2016;175:672-3.

13. Fazendin EA, Crean AJ, Fazendin JM, Kucejko RJ, Gill HS, Poggio $\mathrm{JL}$, et al. Condyloma acuminatum, anal intraepithelial neoplasia, and anal cancer in the setting of HIV: Do we really understand the risk? Dis Colon Rectum. 2017;60:1078-82.

14. Heron SE, Elahi S. HIV infection and compromised mucosal immunity: oral manifestations and systemic inflammation. Front Immunol. 2017;8:1-18.

15. Altman K, Vanness E, Westergaard RP. Cutaneous manifestations of human immunodeficiency virus: a clinical update. Curr Infect Dis Rep. 2015;17:464.

16. Chua SL, Amerson EH, Leslie KS, McCalmont TH, Leboit PE,
Martin JN, et al. Factors associated with pruritic papular eruption of human immunodeficiency virus infection in the antiretroviral therapy era. Br J Dermatol. 2014;170:832-9.

17. Mischo M, von Kobyletzki LB, Bründermann E, Schmidt DA, Potthoff A, Brockmeyer NH, et al. Similar appearance, different mechanisms: xerosis in HIV, atopic dermatitis and ageing. Exp Dermatol. 2014;23:446-8.

18. Lai SW, Lin CL, Liao KF, Chen WC. Herpes zoster could be an early manifestation of undiagnosed human immunodeficiency virus infection. J Formos Med Assoc. 2016;115:372-6.

19. Gilbert L, Wang X, Deiss R, Okulicz J, O’Bryan T, Maves R, et al. Incidence of herpes zoster in a large cohort of persons living with HIV. OFID. 2018;4:S207.

Copyright by Prabhat Singh Rajput, et al. This is an open-access article distributed under the terms of the Creative Commons Attribution License, which permits unrestricted use, distribution, and reproduction in any medium, provided the original author and source are credited.

Source of Support: Nil, Conflict of Interest: None declared. 